\title{
Terrein inhibits migration of human breast cancer cells via inhibition of the Rho and Rac signaling pathways
}

\author{
ANONGNARD KASORN $^{1}$, FABIEN LOISON ${ }^{2,3}$, THANED KANGSAMAKSIN ${ }^{4}$, \\ SUCHADA JONGRUNGRUANGCHOK ${ }^{5}$ and MATHUROSE PONGLIKITMONGKOL ${ }^{4}$
}

\author{
${ }^{1}$ Department of Basic Medical Science, Faculty of Medicine Vajira Hospital, Navamindradhiraj University, Bangkok 10300; \\ ${ }^{2}$ Department of Microbiology, ${ }^{3}$ Systems Biology of Diseases Research Unit and ${ }^{4}$ Department of Biochemistry, \\ Faculty of Science, Mahidol University, Bangkok 10400; ${ }^{5}$ Department of Pharmaceutical Chemistry, \\ Rangsit University, Pathum Thani 12000, Thailand
}

Received July 14, 2017; Accepted December 14, 2017

DOI: $10.3892 /$ or.2018.6189

\begin{abstract}
Breast cancer is the most common cancer in women worldwide. Progression and aggressiveness of breast cancer is usually associated with its migration and invasion abilities. Recently, natural products with potential anticancer activity have become attractive candidates for alternative treatment of cancer. A fungal metabolite, terrein, isolated from the Aspergillus terreus has been revealed to exhibit selective anticancer activity; although this molecule has a variety of biological activities. The inhibitory effect on cell proliferation in hepatoma, keratinocytes, and lung cancer cells was due to cell cycle arrest without induction of apoptosis. In contrast, its effects on cervical and breast cancer cells were mediated through activation of the apoptotic process. However, the effect of terrein on cell migration and invasion has not been explored. In the present study we analyzed the molecular effects of terrein on cell adhesion, cell migration, and cell invasion using two breast cancer cell lines, MCF-7 and MDA-MB-231, which exhibit different levels of invasiveness. Terrein induced apoptosis in both breast cancer cell lines in a dose-dependent manner. In addition, at a non-toxic concentration terrein exhibited a weak inhibition of cell adhesion, using either fibronectin or type IV collagen as substrates. Notably, terrein significantly inhibited both the migration and invasion abilities of MDA-MB-231 cells at the same non-toxic concentration. A marked decrease in MMP-2 and MMP-9 transcripts, as evaluated by real-time PCR, confirmed the antiinvasion effect of terrein at the transcriptional level. Western blot analyses revealed that terrein treatment suppressed RhoB expression and reduced Racl phosphorylation, leading to Rho GTPase inhibition. In addition, terrein-treated MCF-7
\end{abstract}

Correspondence to: Professor Mathurose Ponglikitmongkol, Department of Biochemistry, Faculty of Science, Mahidol University, 272 Rama VI Road, Ratchathewi, Bangkok 10400, Thailand

E-mail: mathurose.pon@mahidol.ac.th

Key words: terrein, migration, breast cancer, Rho, Rac and MDA-MB-231 cells both displayed a scattered pattern of migration, suggesting that the suppression of RhoB and Rac1 disturbed the collective migration processes of breast cancer cells.

\section{Introduction}

Breast cancer is the leading cause of death in women in both developed and developing countries, with an estimated 1.7 million cases and 521,900 deaths in 2012 (1). Although advanced treatments such as surgery, radiotherapy and chemotherapy have been developed, breast cancer incidence and mortality rates continue to increase due to the low efficacy, severe side effects, and lack of access to treatment $(2,3)$. Alternative strategies with fewer adverse effects are therefore necessary to increase current therapies for breast cancer treatment.

For several centuries, natural products have been used to treat diseases in humans. Bacteria, plants and fungi are the major sources of natural products being investigated for their potential as anticancer drugs. An example of a natural product with noteworthy biological activities is the fungal metabolite, terrein, isolated from Aspergillus terreus Thom. Terrein was first described in 1935 and was subsequently isolated from other strains of Aspergillus as well as Emericella and Penicilium (4-6). Terrein exhibits several biological activities including anti-inflammation, anti-melanogenesis, and anticancer properties. Treatment of keratinocytes, hepatoma and lung cell lines with terrein does not stimulate apoptosis $(7,8)$, instead it appears to limit proliferation by promoting cell cycle arrest. Similarly, terrein also inhibited growth and induced cell cycle arrest in a human ovarian cancer cell line (9) and hepatoma Bel-7402 cells (8). However, the activity of terrein is cell type-dependent and this compound not only inhibits cell proliferation but also induces apoptosis. Activation of the caspase-7 pathway and suppression of Akt signaling was observed following exposure of ABCG-2-expressing MCF-7 breast cancer cells to terrein (10). HeLa cervical cancer cells were also sensitive to the anti-proliferation activity of terrein which was mediated through induction of apoptosis (11). In addition, terrein attenuated angiogenin production in head 
and neck cancer cells (12), which may be another underlying mechanism in its anticancer effects. Although terrein has been known for more than 80 years, its biological activities are still poorly understood. Further investigation into its anticancer mechanism, especially on cell migration and invasion will be beneficial for the development of alternative therapeutic measures for breast cancer treatment.

Cell migration and invasion are typically initiated by changes of the extracellular matrix leading to alterations in cell adhesion, the cytoskeleton as well as stimulation of intracellular signaling pathways (13). Upon stimulation by a change in a chemokine gradient, cell migration begins by altering the dynamics of actin polymerization which is highly coordinated with cell movement through the extracellular matrix. The matrix metalloproteinases (MMPs) are crucial for degradaing the extracellular matrix facilitating migration. In addition, the Rho family of small GTPases play key roles in regulating the cell migration process (14). Among the 22 Rho family proteins so far identified, RhoA/B/C, Rac1/2/3 and $\mathrm{Cdc} 42$ are the best characterized and all have been implicated in the regulation of cell migration (15-17). In untransformed cells, Rho GTPases are involved in the control of cell morphology and motility, while Cdc42 regulates the extension of filopodia and lamellipodia formation at the leading edge of the cell (18). RhoA is involved in the generation of the contractile force as well as moving the body and tail of the cell (18). RhoB appears to regulate membrane trafficking, cell proliferation, DNA-repair, and apoptosis (19). In addition, RhoC plays a critical role in the dynamic of actin polymerization at the leading edge of the cell, promoting cell motility (20). Rac1 which regulates the assembly of actin filament networks has also been demonstrated to enhance cell invasiveness upon activation (21).

In the present study, to better understand the anticancer properties of terrein the contribution of Rho GTPases and MMPs on cell migration and invasion in breast cancer cells were examined.

\section{Material and methods}

Materials and chemicals. DMEM culture medium was purchased from Gibco/Thermo Fisher Scientific, Inc. (Rockville, MD, USA). Fetal bovine serum (FBS), penicillinstreptomycin cocktail, $0.25 \%(\mathrm{w} / \mathrm{v})$ trypsin/1 mM EDTA and SuperScript ${ }^{\circledR}$ III RNase H-RT kit were purchased from Invitrogen/Thermo Fisher Scientific, Inc. (Carlsbad, CA, USA). Fibronectin from human plasma, type IV collagen from human placenta, 3-(4,5-dimethyl-2-thaizol)-2,5-diphenyltetrazolium bromide (MTT) were supplied by Sigma-Aldrich (St. Louis, MO, USA). Matrigel was obtained from BD Biosciences (Bedford, MA, USA). The Annexin V/7AAD apoptosis detection kit was supplied by BioLegend, Inc. (San Diego, CA, USA).

Cell culture. Human breast cancer cell lines, MCF-7 (cat no. HTB-22) and MDA-MB-231 (cat. no. HT-B26; both from ATCC, Manassas, VA, USA) were grown in Dulbecco's modified Eagle's medium (DMEM) supplemented with $10 \%$ heat-inactivated fetal bovine serum, $100 \mathrm{U} / \mathrm{ml}$ penicillin and $100 \mu \mathrm{g} / \mathrm{ml}$ streptomycin (complete DMEM) in a humidified atmosphere containing $5 \% \mathrm{CO}_{2}$ at $37^{\circ} \mathrm{C}$. Cells were sub-cultured two or three times a week to maintain their viability.

Preparation ofterrein.Isolation of terrein(Fig. 1) was performed as previously described (11). Briefly, an ethyl acetate (EtOAc) extract from the culture broth of Aspergillus terreus CRI301 was concentrated in vacuo, fractioned and purified by Sephadex $^{\mathrm{TM}}$ LH-20 using $\mathrm{MeOH}$ as an eluent. The compound was then characterized by spectroscopic analysis. The purity of terrein was $\sim 80 \%$ as determined by LCMS.

Cell viability assay. The effect of terrein on breast cancer cell viability was determined using the MTT assay. MCF-7 and MDA-MB-231 cells were seeded at the density of $1 \times 10^{5}$ cells/well on $96-$ well plates. The following day, the cells were treated with various concentrations of terrein and cultured for an additional 24 or $48 \mathrm{~h}$. After the incubation period, DMEM was removed and MTT solution $(0.5 \mathrm{mg} / \mathrm{ml})$ was added to each well and incubation followed for $4 \mathrm{~h}$ at $37^{\circ} \mathrm{C}$. The formazan product was solubilized by the addition of $100 \mu \mathrm{l}$ of DMSO and the absorbance (OD) at $540 \mathrm{~nm}$ was assessed using a microplate reader. The ratio of the OD of treated cells relative to those of the control cells was calculated and expressed as the percentage of cell viability.

Cell adhesion assay. The 96-well plates were coated with either $10 \mu \mathrm{g} / \mathrm{ml}$ of fibronectin or type IV collagen overnight at $4^{\circ} \mathrm{C}$. Nonspecific binding was blocked with $1 \%$ bovine serum albumin (BSA) for $1 \mathrm{~h}$ at $37^{\circ} \mathrm{C}$, followed by washing three times with phosphate-buffered saline (PBS). MCF-7 and MDA-MB-231 cells at $80 \%$ confluence were treated with vehicle or terrein $(25$ and $75 \mu \mathrm{M})$ for $24 \mathrm{~h}$. The cells were then trypsinized, resuspended in medium without serum and plated at the density of $1 \times 10^{4}$ cells into each well. The cells were allowed to adhere at $37^{\circ} \mathrm{C}$, in a $5 \% \mathrm{CO}_{2}$ atmosphere for 30 and $60 \mathrm{~min}$. Non-adherent cells were removed by washing three times with $100 \mu \mathrm{l}$ PBS. Adherent cells were fixed with $4 \%$ paraformaldehyde and stained with $2.5 \%$ crystal violet in methanol. Cells were dissolved with $25 \%$ acetic acid and the absorbance was assessed at $540 \mathrm{~nm}$ using VersaMax ELISA Microplate Reader (Molecular Devices, Sunnyvale, CA, USA).

Wound healing assay. MCF-7 and MDA-MB-231 cells were seeded onto $60-\mathrm{mm}^{2}$ dishes at a density of $5 \times 10^{5}$ cells/dish in DMEM containing $10 \%$ FBS. Cells at near confluence were then starved with serum-free DMEM for $24 \mathrm{~h}$. Wounding was simulated by drawing a scratch on the cell monolayer with a $20 \mu 1$ pipette tip, and debris was removed by washing with serum-free DMEM. Cells were then incubated with or without terrein $(25$ and $75 \mu \mathrm{M})$ for $24 \mathrm{~h}$ in complete DMEM. Images of cells migrating into the wound area were captured from different fields at 0 and $24 \mathrm{~h}$ with a light microscope at a magnification of $x 400$. The open wound areas were assessed using TScratch software (22) and the results are presented as the percentage of closed wound areas.

Cell migration assay. In vitro migration assays were performed using a 24-well Transwell chamber with a polycarbonate membrane containing $8.0-\mu \mathrm{m}$ pores (Corning Costar, Cambridge, MA, USA). MCF-7 and MDA-MB-231 cells were 
grown to $80 \%$ confluence and serum-starved overnight prior to migration experiments. Cells $\left(2 \times 10^{5}\right)$ in DMEM serum-free media were plated into the upper chamber with or without terrein (25 and $75 \mu \mathrm{M})$. The lower chamber contained DMEM with 5\% FBS which acted as a chemoattractant. After $24 \mathrm{~h}$ at $37^{\circ} \mathrm{C}$ in $5 \% \mathrm{CO}_{2}$, the experiment was stopped by wiping the non-migrated cells from the top of the membrane with a cotton swab. Migrated cells on the bottom of the membrane were fixed with $4 \%$ paraformaldehyde for $5 \mathrm{~min}$, stained with $2.5 \%$ crystal violet in methanol for $10 \mathrm{~min}$ and washed with water to remove the excess dye. The migrated cells on the membrane were dissolved with $25 \%$ acetic acid and quantitated by assessing the absorbance at $540 \mathrm{~nm}$ using VersaMax ELISA Microplate Reader (Molecular Devices).

Cell invasion assay. In vitro invasion assay was also performed using a 24-well Transwell chamber with a polycarbonate membrane containing $8.0-\mu \mathrm{m}$ pores. The method was identical to the migration assay previously described with the exception that the inserts were coated with $100 \mu$ l Matrigel $^{\circledR}$ (BD Biosciences) diluted to $1 \mathrm{mg} / \mathrm{ml}$.

Reverse transcription $(R T)$ and real-time PCR. Cells were lysed and total RNA was extracted with the Illustra ${ }^{\mathrm{TM}}$ RNAspin mini kit (GE Healthcare, Little Chalfont, UK) according to the manufacturer's instructions. Isolated RNA was used as a template for cDNA synthesis employing the SuperScript ${ }^{\circledR}$ III RNase H-RT kit (Invitrogen/Thermo Fisher Scientific, Inc.). Real-time PCR was performed with a Stratagene Mx3000P qPCR system (Agilent Technologies, Santa Clara, CA, USA) utilizing RBC ThermOne ${ }^{\circledR}$ Real-Time Premix (SYBR-Green) (RBC Bioscience Corp., New Taipei City, Taiwan). All reactions were carried out using the following conditions: $10 \mathrm{~min}$ at $95^{\circ} \mathrm{C}$; $30 \mathrm{sec}$ at $95^{\circ} \mathrm{C}, 30 \mathrm{sec}$ at $60^{\circ} \mathrm{C}$ and $30 \mathrm{sec}$ of $72^{\circ} \mathrm{C}$ (40 cycles). Determination of the expression of hypoxanthine-guanine phosphoribosyltransferase (HPRT), a housekeeping gene, was included in each experiment to correct for variations in template concentrations. The amounts of PCR amplicons were analyzed using Gel Doc 2000 and Quantity One software package (BioRad Laboratories, Inc., Hercules, CA, USA). Primers used for the amplification of MMP-2, MMP-9 and the internal control HPRT have been previously described $(23,24)$ with the following sense and antisense primer sets: MMP-2 forward, 5'-GTTCATTTGGCGGACTGTGACG-3' and reverse, 5'-ATT CATTCCCTGCAAAGAACACAGC-3'; MMP-9 forward, 5'-CACGACGTCTTCCAGTACCGAGA-3' and reverse, 5'-CAT AGGTCACGTAGCCCACTTGGT-3'; and HPRT forward, 5'-TGTGATGAAGGAGATGGG AGG-3' and reverse, 5'-AAG CTTGCGACCTTGACCATCT-3'. The method was used for determination of relative fold of gene expression (25).

Apoptosis assay using flow cytometer. MCF-7 and MDA-MB-231 cells $\left(5 \times 10^{5}\right)$ cells were seeded onto $60-\mathrm{mm}^{2}$ plates in DMEM containing $10 \% \mathrm{FBS}$ for $24 \mathrm{~h}$ prior to the apoptosis assay. Cells were then cultured in the presence of DMSO or increasing concentrations of terrein for $24 \mathrm{~h}$. For each condition, adherent cells were detached using Trypsin-EDTA and pooled with the cells collected in the corresponding culture supernatant. Cells were washed twice with ice-cold PBS and subsequently stained with Annexin V-7AAD (PerCP/Cy5.5)
(BioLegend) in Annexin $\mathrm{V}$ binding buffer for $15 \mathrm{~min}$. Samples were analyzed using a Beckman-Coulter CytoFLEX (Beckman-Coulter, Brea, CA, USA). Analysis was performed using CytExpert software (Beckman-Coulter).

Western blot analysis. Small GTPases were analyzed by western blotting using Rho-GTPase Antibody Sampler kit (cat no. 9968; Cell Signaling Technology, Inc., Danvers, MA, USA). Equal amounts of total protein were separated by SDS-PAGE and then transferred onto a PDVF membrane. The membrane was incubated with the following primary antibodies: Cdc42 (1:1,000; rabbit mAb; cat. no. 11A11), phospho-Rac1/cdc42 (Ser71) (1:1,000; rabbit pAb), RhoA (1:1,000; rabbit mAb; cat. no. 67B9), RhoB (1:1,000; rabbit pAb), RhoC (1:1,000; rabbit mAb; cat. no. D40E4), or Rac1/2/3 (1:1,000; rabbit pAb) for $1 \mathrm{~h}$ at room temperature, and the secondary antibody $(1: 1,000$; anti-rabbit IgG, HRP-linked) for $1 \mathrm{~h}$ at room temperature, respectively. All lanes presented in one western blot strip were derived and adjusted equally from the same corresponding blot using $\beta$-actin (1:1,000; rabbit mAb; cat no. 4970; Cell Signaling Technology, Inc.) as a normalizing control.

Statistical analysis. All assays were performed in triplicate. Statistical analyses were performed using GraphPad Prism 5 software (GraphPad Software, Inc., La Jolla, CA, USA). All data are presented as the mean \pm standard deviation (SD). Statistical differences were determined by unpaired Student's t-test with Welch's correction. $\mathrm{P}<0.05$ was considered to indicate a statistically significant difference.

\section{Results}

Effect of terrein on the viability of breast cancer cells. MCF-7 and MDA-MB-231 cells were treated with increasing concentrations of terrein from 0 to $500 \mu \mathrm{M}$ for 24 and $48 \mathrm{~h}$. The cytotoxicity of terrein was evaluated using MTT assays. The results demonstrated that terrein reduced the viability of these cells in concentration- and time-dependent manners (Fig. 2A and Table I). Terrein exhibited similar effects on both cell lines revealing a significant reduction in cell viability following exposure to $100-500$ and $50-500 \mu \mathrm{M}$ at 24 and $48 \mathrm{~h}$, respectively (Table I). The $\mathrm{IC}_{50}$ values of terrein for MCF-7 and MDA-MB-231 cells after $24 \mathrm{~h}$ of incubation were $2.34 \mathrm{mM}$ and $700 \mu \mathrm{M}$, respectively (data not shown). After $48 \mathrm{~h}$ of incubation, the $\mathrm{IC}_{50}$ value of terrein was $244.3 \mu \mathrm{M}$ for MCF-7 and 244.5 $\mu \mathrm{M}$ for MDA-MB-231 cells (data not shown). Moreover, the effect of terrein on the cell viability of Vero cells, (an African green monkey kidney cell line), which were used as a normal control, was determined. At both time-points, a significant decrease in cell viability of Vero cells was observed with an estimated $\mathrm{IC}_{50}$ of 646 and $690.8 \mu \mathrm{M}$ at 24 and $48 \mathrm{~h}$, respectively (data not shown).

To determine whether the reduction of cell viability detected using MTT assays was due to cell death or the inhibition of cell cycle progression, we performed flow cytometry and Annexin V-7AAD staining. As shown in Fig. 2B, the percentage of cells undergoing apoptosis (Annexin V-positive) increased in a concentration-dependent fashion for both MCF-7 and MDA-MB-231 cells. Our results revealed that a high concentration of terrein induced programmed cell death 
Table I. Effects of terrein on viability of breast cancer cells.

Cell viability ( $\%$ of control)

\begin{tabular}{|c|c|c|c|c|}
\hline \multirow[b]{2}{*}{ Terrein $(\mu \mathrm{M})$} & \multicolumn{2}{|c|}{ MCF-7 } & \multicolumn{2}{|c|}{ MDA-MB-231 } \\
\hline & $24 \mathrm{~h}$ & $48 \mathrm{~h}$ & $24 \mathrm{~h}$ & $48 \mathrm{~h}$ \\
\hline 5 & $103.274 \pm 2.621$ & $94.342 \pm 2.244$ & $106.246 \pm 4.820$ & $102.495 \pm 7.324$ \\
\hline 25 & $98.305 \pm 1.848$ & $92.211 \pm 6.667$ & $100.780 \pm 6.892$ & $98.737 \pm 2.025$ \\
\hline 50 & $103.342 \pm 6.775$ & $88.261 \pm 2.985^{\mathrm{a}}$ & $103.812 \pm 2.611$ & $98.810 \pm 5.138$ \\
\hline 75 & $92.263 \pm 5.822$ & $79.650 \pm 3.324^{b}$ & $94.050 \pm 7.422$ & $84.064 \pm 3.242^{a}$ \\
\hline 100 & $85.894 \pm 3.954^{\mathrm{a}}$ & $70.998 \pm 3.972^{b}$ & $84.042 \pm 2.005^{\mathrm{b}}$ & $66.231 \pm 5.003^{\mathrm{t}}$ \\
\hline 150 & $87.593 \pm 6.205$ & $65.649 \pm 1.752^{\mathrm{c}}$ & $76.294 \pm 1.027^{\mathrm{c}}$ & $54.368 \pm 4.322^{\mathrm{b}}$ \\
\hline 250 & $78.099 \pm 2.840^{\mathrm{b}}$ & $53.384 \pm 0.568^{\mathrm{d}}$ & $63.480 \pm 0.328^{\mathrm{d}}$ & $44.623 \pm 5.688^{\mathrm{t}}$ \\
\hline 500 & $53.398 \pm 0.856^{\mathrm{c}}$ & $41.970 \pm 2.830^{c}$ & $36.144 \pm 0.951^{\mathrm{d}}$ & $23.863 \pm 2.463^{\circ}$ \\
\hline
\end{tabular}

${ }^{\mathrm{a}} \mathrm{P}<0.05,{ }^{\mathrm{b}} \mathrm{P}<0.01,{ }^{\mathrm{c}} \mathrm{P}<0.005$ and ${ }^{\mathrm{d}} \mathrm{P}<0.001$.

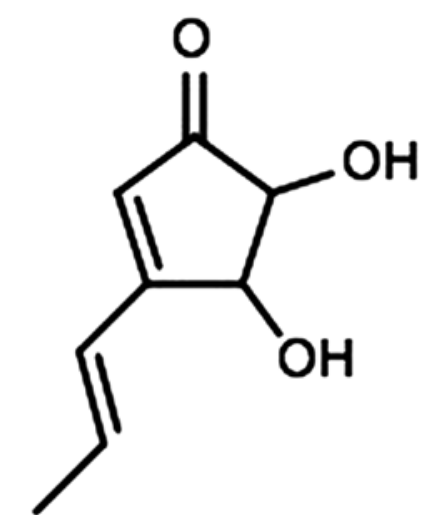

Figure 1. Chemical structure of terrein.

in both invasive and non-invasive breast cancer cell lines. Thus, the optimal non-toxic concentrations of terrein (25 and $75 \mu \mathrm{M}$ ) were used for subsequent experiments.

Effect of terrein on the adhesion of breast cancer cells. Adhesion is one of the essential steps in cancer cell metastasis. We performed cell adhesion assays in order to determine the effect of terrein on breast cancer cell adhesion. MCF-7 and MDA-MB-231 cells were allowed to adhere on either a fibronectin- or type IV collagen-coated surface for 30 and 60 min. As shown in Fig. 3A, terrein significantly decreased MCF-7 cell adhesion on fibronectin and type IV collagen revealing $\sim 30 \%$ inhibition. Although adhesion of terreintreated MDA-MB-231 cells on type IV collagen was not impaired, cell adhesion on fibronectin was reduced by $20 \%$ for MDA-MB-231 cells exposed to $75 \mu \mathrm{M}$ of terrein (Fig. 3B). These results demonstrated the selective inhibitory effect of terrein on the adhesion of breast cancer cells.

Effect of terrein on the migration of breast cancer cells. To evaluate the effect of terrein on breast cancer cell migration, a wound-healing assay was performed. Scrape wounds were created on slides containing confluent breast cancer cell lines. After treatment with terrein, cancer cells were allowed to migrate to the wound area for $24 \mathrm{~h}$. As shown in Fig. 4A, untreated MDA-MB-231 cells almost closed the wound area after 24 h of incubation ( $85 \%)$, whereas MCF-7 cells closed only $\sim 25 \%$ of the wound area. As indicated by the densitometric analyses (Fig. 4B), terrein at $75 \mu \mathrm{M}$ significantly decreased MCF-7 and MDA-MB-231 cell migration after incubation for 24 h by $\sim 10$ and $40 \%$, respectively.

The ability of terrein to impair breast cancer cell migration was further confirmed using Transwell assays with 5\% FBS as a chemoattractant. Migration of MCF-7 cells treated with $75 \mu \mathrm{M}$ terrein was significantly reduced after $24 \mathrm{~h}$ of incubation (Fig. 4C). Notably, terrein exhibited even stronger inhibitory effects on MDA-MB-231 cells, reducing cell migration by 30 and $70 \%$ at 25 and $75 \mu \mathrm{M}$ terrein, respectively. These results indicated that terrein inhibited the migration of breast cancer cells.

Effect of terrein on breast cancer cell invasion. We further examined the effect of terrein on breast cancer cell invasion using the Transwell assay containing a Matrigel coating. MCF-7 and MDA-MB-231 cells were allowed to invade through Matrigel in the presence of terrein for $24 \mathrm{~h}$. The invasive ability of MCF-7 cells exposed to terrein was significantly reduced by $\sim 20 \%$ (Fig. 4D and E). Although at a low concentration $(25 \mu \mathrm{M})$ terrein only slightly impaired MDA-MB-231 cell invasion, a marked reduction of $50 \%$ was observed in these cells treated with $75 \mu \mathrm{M}$ of terrein, a nontoxic dose (Fig. 4D and F). Therefore, these results confirmed the inhibitory effects of terrein on breast cancer cell migration and invasion.

Effect of terrein on the expression of MMP-2 and MMP-9. MMPs play an important role in cancer cell invasion and metastasis, and MMP-2 and MMP-9 are known to be essential for breast cancer progression (26). Real-time PCR was used to examine whether the anti-invasive property of terrein was correlated with altered expression levels of MMP-2 and MMP-9. As revealed in Fig. 5, terrein decreased the mRNA levels of both MMP-2 and MMP-9 in a concentrationdependent manner. Significant decreases were observed in 
A

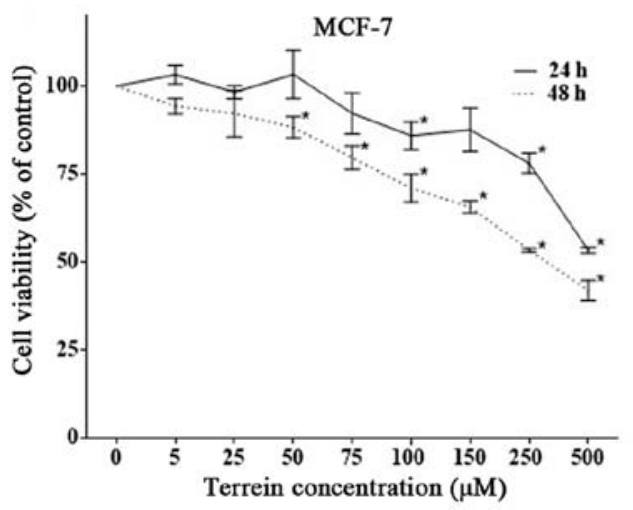

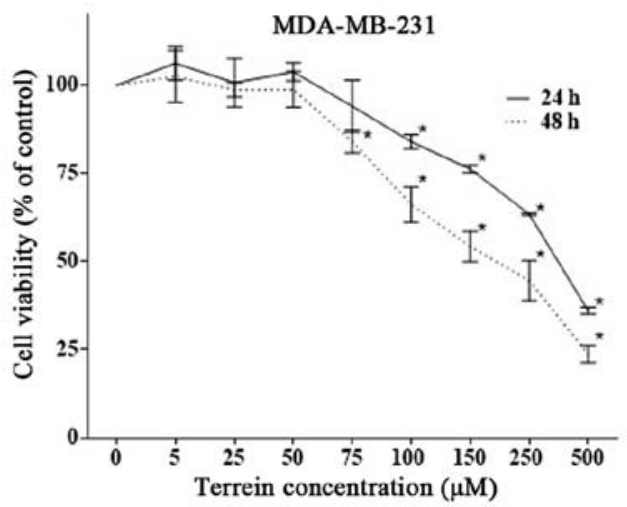

Terrein
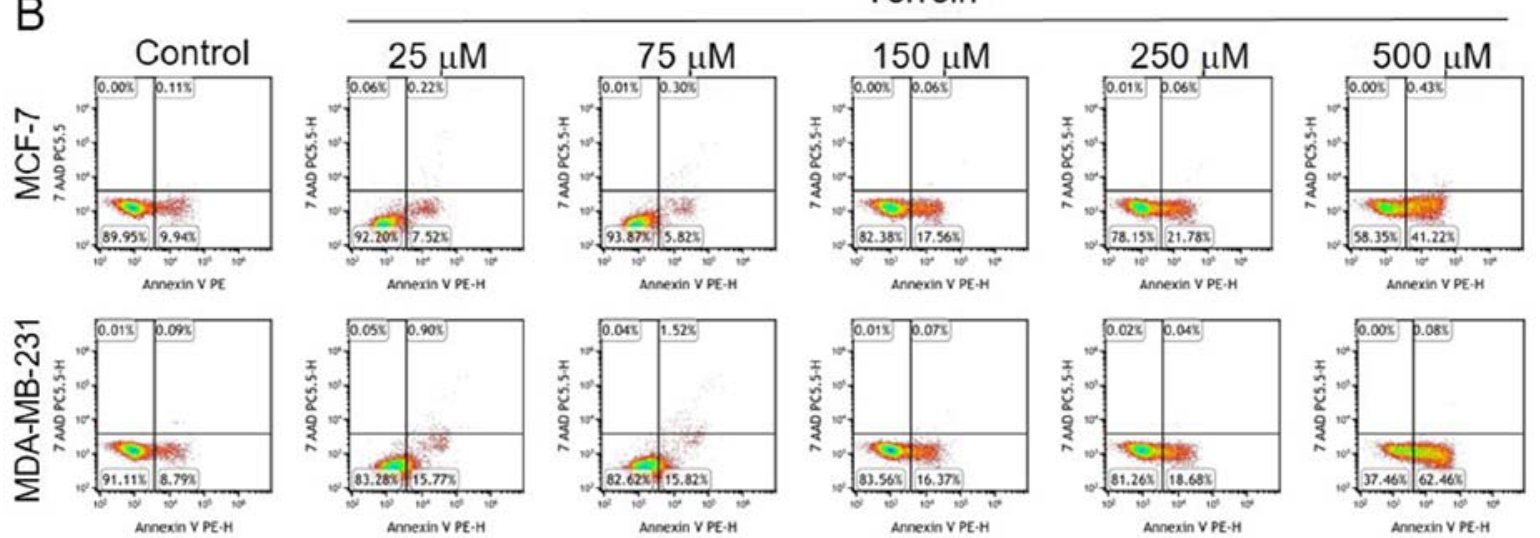

Figure 2. Effects of terrein on the viability of breast cancer cells. (A) MCF-7 and MDA-MB-231 cells were treated with different concentrations of terrein for 24 and $48 \mathrm{~h}$. The absorbance of fthe ormazan product was assessed at $540 \mathrm{~nm}$. The viability of breast cancer cells was calculated and presented as the percentage of the control ( $\mathrm{P}<0.05)$. (B) MCF-7 and MDA-MB-231 cells treated with different concentrations of terrein for 24 h. The percentages of apoptotic cells were assessed via flow cytometry using Annexin V-7AAD staining and indicated in the lower right quadrant of the figure. The percentages of apoptotic cells after 25 and $75 \mu \mathrm{M}$ of terrein treatment were 7.52 and 5.82\%, respectively for MCF-7 cells (9.94\% for the control), and 15.77 and $15.82 \%$, respectively for MDA-MB-231 cells (8.79\% for the control).
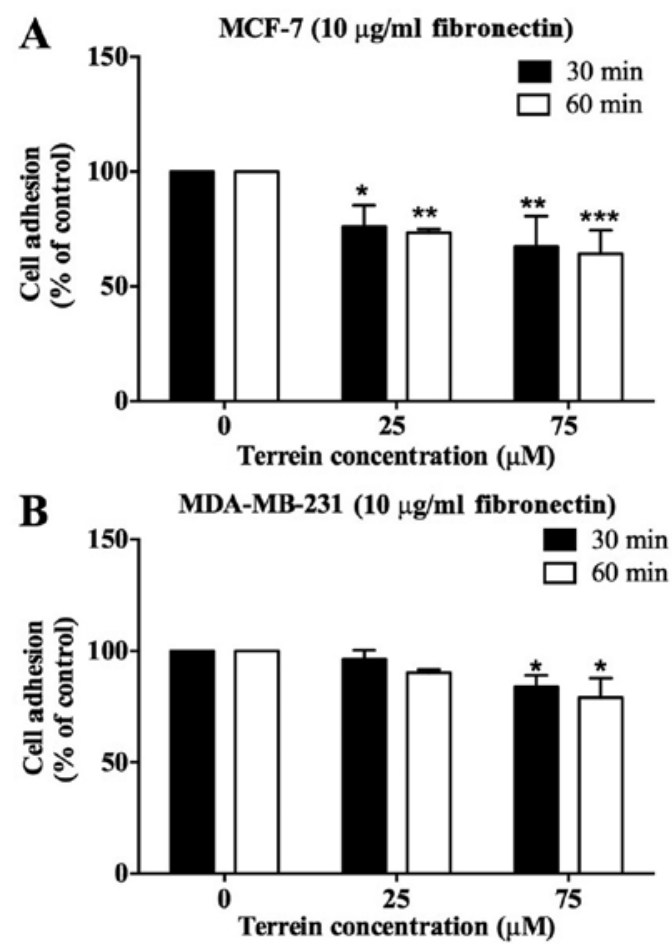
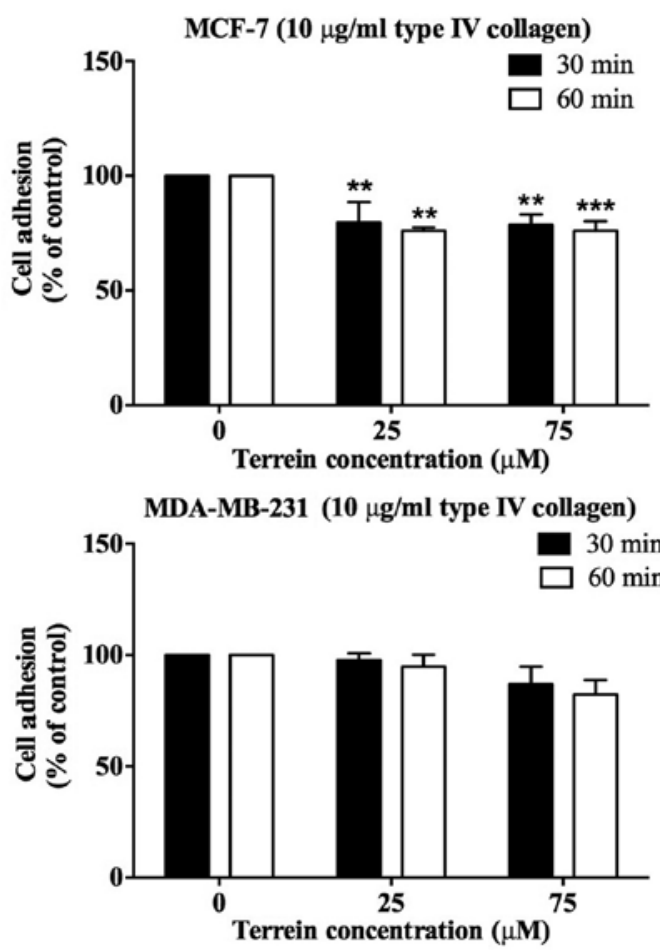

Figure 3. Effects of terrein on the adhesion of breast cancer cells. MCF-7 and MDA-MB-231 cells were treated with 25 and $75 \mu \mathrm{M}$ of terrein for $24 \mathrm{~h}$ and allowed to adhere on either a $10 \mu \mathrm{g} / \mathrm{ml}$ fibronectin- or a collagen type IV-coated surface for 30 and 60 min. (A) Adhesion of MCF-7 cells was significantly decreased on the fibronectin- and type IV collagen-coated surface, while that of (B) MDA-MB-231 cells was significantly reduced only on the fibronectin-coated surface. 
A
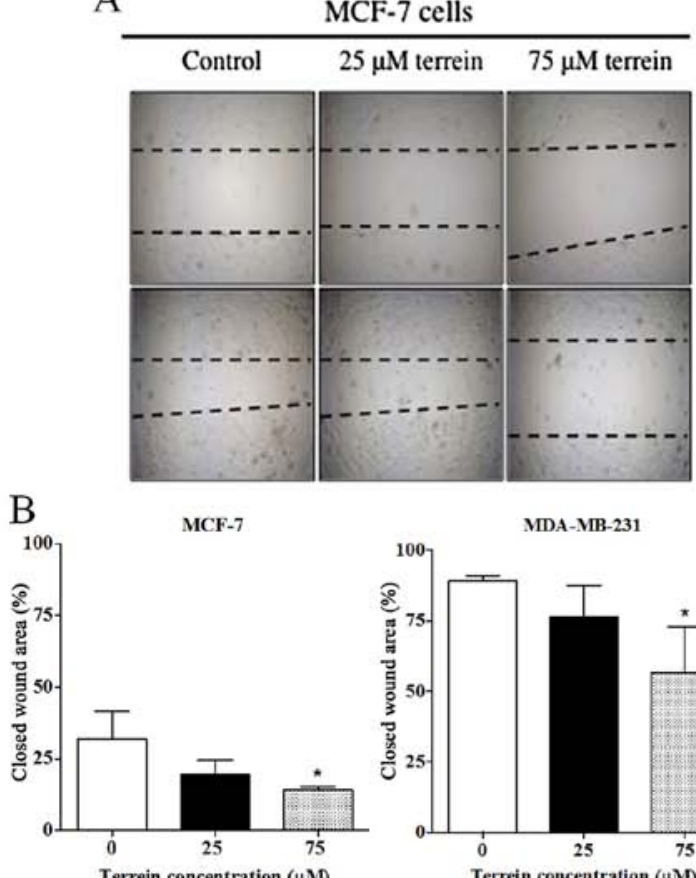

$\mathrm{D}$

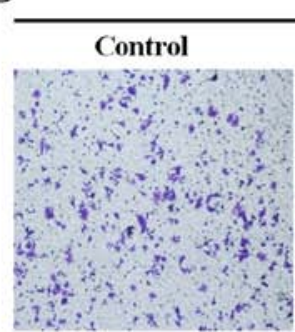

MCF-7 cells

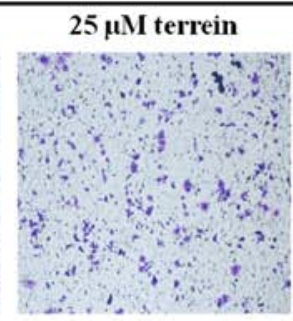

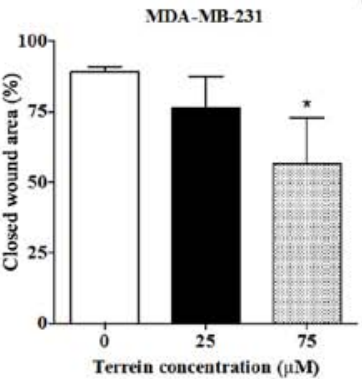

MDA-MB-231 cells

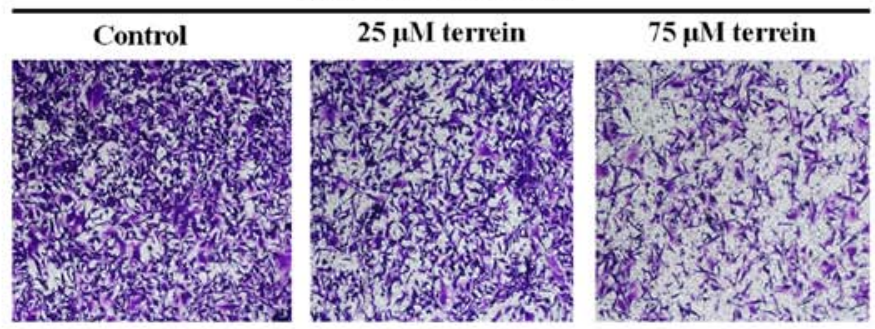

MDA-MB-231 cells
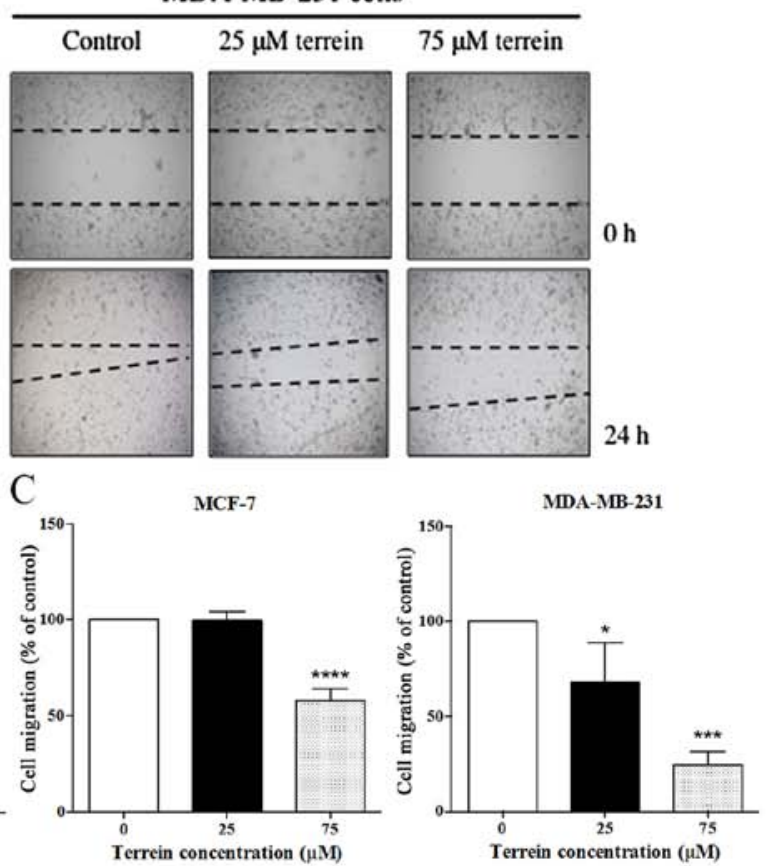

$\mathrm{E}$

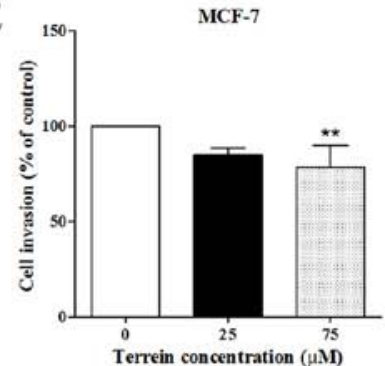

MIDA-MB-231

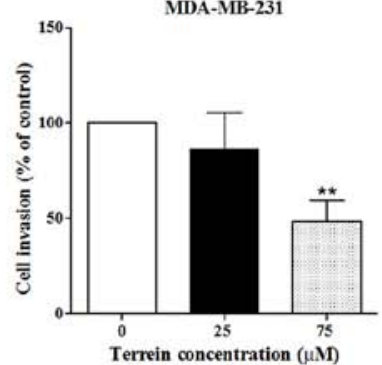

Figure 4. Terrein inhibits breast cancer cell migration and invasion. (A) The wound areas of MCF-7 and MDA-MB-231 cells before and after 24 h of treatment with 25 and $75 \mu \mathrm{M}$ of terrein were assessed, and the percentage of the closed wound areas was calculated. (B) The \% of the closed wound area of MCF-7 and MDA-MB-231 cells treated with $75 \mu \mathrm{M}$ terrein were $14.79 \pm 0.41$ and $56.64 \pm 16.31 \%$, respectively which were statistically significant compared with the control $\left({ }^{*} \mathrm{P}<0.05\right)$. MCF-7 and MDA-MB-231 cells treated with terrein were allowed to migrate through the polycarbonate membrane or Matrigel for 24 h. Cells that migrated and invaded through the membrane were fixed and stained with $2.5 \%$ crystal violet and the absorbance was assessed at $540 \mathrm{~nm}$. (C) The percentages of cell migration compared with the control for $75 \mu \mathrm{M}$ of terrein-treated MCF-7 and MDA-MB-231 cells were 58.17 \pm 5.86 and $24.53 \pm 6.92 \%$, respectively $\left({ }^{* * *} \mathrm{P}<0.005\right)$. At $25 \mu \mathrm{M}$, terrein significantly inhibited migration of MDA-MB-231 cells $\left({ }^{*} \mathrm{P}<0.05\right)$. (D) Representative images of invaded cells (magnification, $\mathrm{x} 40$ ) after treatment with indicated concentrations of terrein compared to the control cells. (E) The percentages of invaded cells treated with $75 \mu \mathrm{M}$ of terrein were $78.54 \pm 11.37 \%$ for MCF-7 and $48.52 \pm 10.81 \%$ for MDA-MB-231 cells, compared with the control cells set as $100 \%\left({ }^{* *} \mathrm{P}<0.01\right)$.

MDA-MB-231 cells treated with 25 and $75 \mu \mathrm{M}$ of terrein, and in the $75-\mu \mathrm{M}$ terrein-treated MCF-7 cells.

Effect of terrein on the expression of RhoA, RhoB, RhoC, p-Racl and $C d c 42$. We next investigated the molecular mechanism through which terrein inhibited breast cancer cell migration and invasion at non-toxic concentrations. Rho GTPases regulate signaling pathways that link cell surface receptors to a wide range of cellular responses, including actin cytoskeleton dynamics (27). Rho regulates the assembly of contractile, actin-myosin filaments. In contrast, Rac and Cdc42 regulate Arp $2 / 3$ complex-mediated actin polymerization controlling the formation of cell protrusions (lamellipodia and filopodia) which are involved in cell migration and invasion (27). As shown in Fig. 6, RhoA and RhoB protein levels were significantly decreased after $6 \mathrm{~h}$ of $75 \mu \mathrm{M}$ terrein treatment in MCF-7 cells. Phosphorylated (p)-Rac1 was also slightly decreased at $12 \mathrm{~h}$. However, RhoC and 

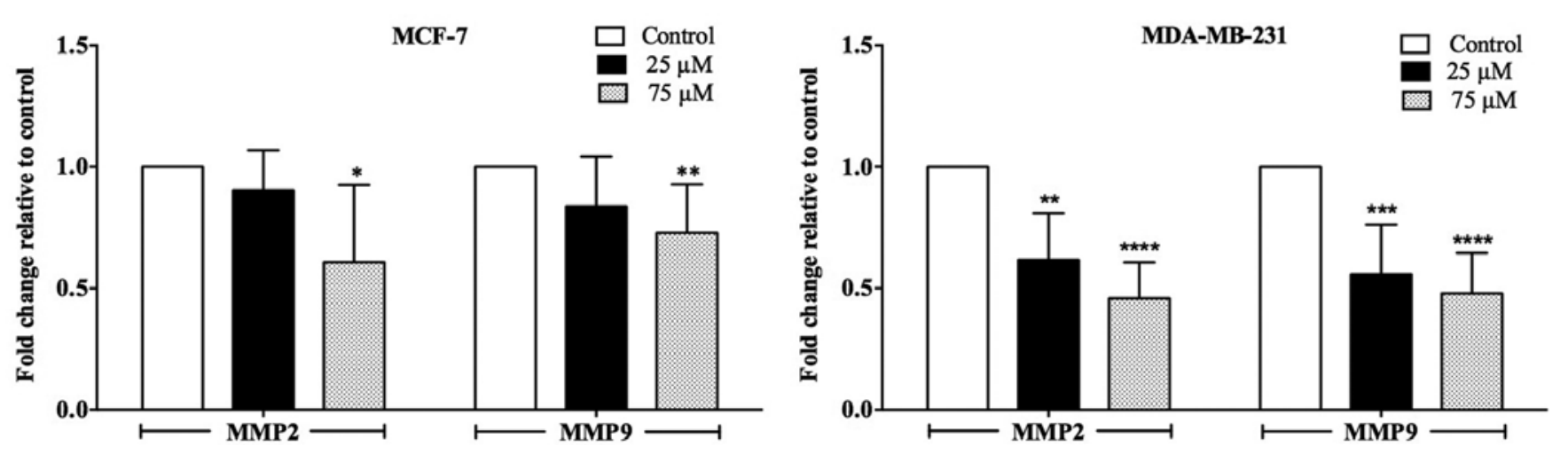

Figure 5. Effect of terrein on the expression of MMP-2 and MMP-9 as determined by real-time PCR. Results from real-time PCR demonstrated a significant decrease in mRNA expression levels of MMP-2 and MMP-9 in terrein-treated MCF-7 and MDA-MB-231 cells ${ }^{*} \mathrm{P}<0.05,{ }^{* *} \mathrm{P}<0.01$ and ${ }^{* * *} \mathrm{P}<0.005$.
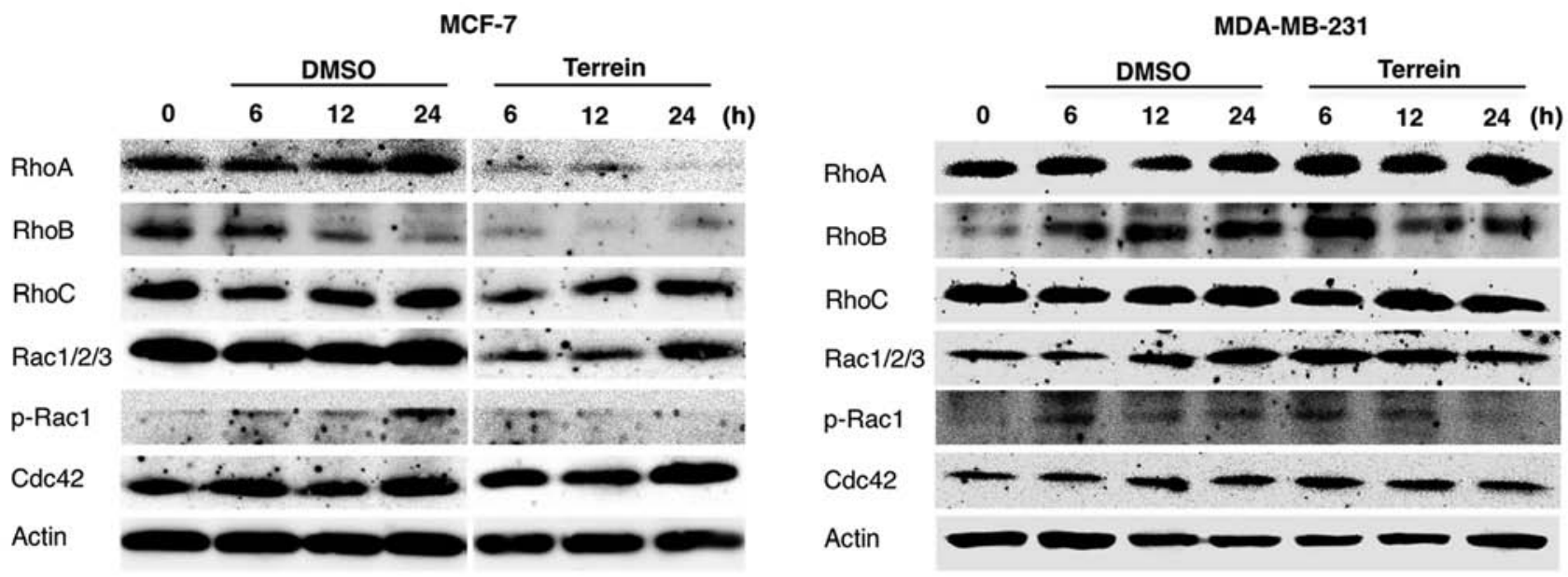

Figure 6. Effect of terrein on the expression of Rho, Rac and $\mathrm{Cdc} 42$ as analyzed by western blotting using $\beta$-actin as a loading control. The expression of RhoA, RhoB, RhoC, Rac1/2/3, p-Rac1 and Cdc42 in MCF-7 and MDA-MB-231 cells after exposure to $75 \mu \mathrm{M}$ of terrein were assessed at $0,6,12$ and 24 h. DMSO was used as a test control.

Cdc42 levels remained unchanged. RhoB protein levels and Rac1 phosphorylation were also decreased in MDA-MB-231 cells in the presence of terrein, at 12 and $24 \mathrm{~h}$, respectively. Therefore, inhibition of RhoB and Racl by terrein may disrupt actin cytoskeletal formation and arrangement leading to a decrease in cell migration. This hypothesis was supported by our observation that terrein treatment induced a scattered pattern of migration for both MCF-7 and MDA-MB-231 cells (Fig. 4A). Thus, terrein-induced suppression of RhoB and Racl expression appeared to disturb the overall migration processes.

\section{Discussion}

Breast cancer cells often acquire more aggressive phenotypes at later stages, with increased cell growth, migration, and invasion capabilities. Suppression or prevention of these properties could significantly inhibit cancer progression and improve disease outcome. Terrein, a compound from Aspergillus terreus, is a notable candidate for breast cancer treatment with several noteworthy anticancer properties, and also exhibits inhibitory activity on breast cancer resistance protein (28). However, its effects on cell migration and invasion ability have not been examined.
In the present study, biological activities and the molecular effects of terrein on adhesion, migration and invasion of MCF-7 and MDA-MB-231 breast cancer cells were investigated in vitro. Our results revealed that the anticancer activities of terrein were mediated through several processes. Terrein exhibited cytotoxic effects by inhibiting proliferation of both MCF-7 and MDA-MB-231 breast cancer cells at a high concentration $(150 \mu \mathrm{M})$. However, using Annexin V staining and flow cytometry, we observed that MCF-7 and MDA-MB231 cells underwent apoptosis upon treatment at a low concentration of terrein $(75 \mu \mathrm{M})$. Cytotoxicity of this metabolite has been previously reported in different cell lines. Terrein induced apoptosis in HeLa cells due to the activation of p53 and the intrinsic apoptosis pathway (11). Apoptosis observed in ABCG2-expressing MCF7 cells was a consequence of the activation of caspase-7 and the inhibition of Akt signaling (10). Terrein was also demonstrated to induce cell-cycle arrest in ovarian cancer cells (9). Demasi et al revealed that proapoptotic activity of terrein on the human tumoral cell line NCI-H292 was due to the inhibition of the proteasome (29). Proteasome inhibitiors such as botezomib, induce apoptosis and cell-cycle arrest, and have been approved for the treatment of cancers (30). Notably, the inhibition of ERK or AKT signaling is often observed in terrein-treated cells even in the 
absence of apoptosis $(7,31,32)$ and the inhibition of ERK and Akt phosphorylation has been reported following proteasome inhibition (33). One hypothesis is that the differential outcome of terrein treatment on various cell lines may be due to their susceptibility to inhibition of the proteasome.

At a non-toxic dose $(75 \mu \mathrm{M})$, terrein could clearly inhibit wound healing, cell migration and cell invasion of breast cancer cells, and this was more clearly observed in aggressive MDA-MB-231 cells. Cell adhesion assays revealed that terrein significantly reduced adhesion mediated by both type IV collagen and fibronectin, with a greater effect on MCF-7 cells. These results indicated that terrein could suppress cancer progression at several steps.

Rho GTPases have been reported to be essential for both cancer initiation and progression during tumorigenesis (34), implicating their potential for use as a molecular target for cancer treatment. Although mutations of RHO genes are rare in tumors, dysregulation of their expression and activity is frequently reported. Overexpression of RhoA was detected in colon, lung as well as breast cancers (35). Moreover, depletion of Rac1 was reported to inhibit migration and invasion of carcinoma and melanoma cells $(36,37)$. The inhibition of Cdc42 abolished a mesenchymal-amoeboid transition, subsequently impairing melanoma cell invasion (37). Further investigation into the RHO family demonstrated that terrein exhibited a consistent inhibitory effect on the levels of RhoB and Rac in both breast cancer cell lines. The ability of terrein to inhibit migration and invasion of MCF-7 and MDA-MB-231 cells appeared to be related to the reduction of protein levels for the Rho GTPases. The effects of impaired Rho GTPases on cancer survival and migration have previously been reported. Rac-specific inhibitor targeting Rac-GEF suppressed prostate cancer cell proliferation and invasion $(38,39)$. Similarly, a Cdc42/Rac1 GTPase inhibitor was revealed to significantly decrease the growth of prostate cancer and improve survival in vivo (40). The increased scattered pattern of migration of MCF-7 and MDA-MB-231 cells in the presence of terrein suggested the possible disruption of cytoskeleton reorganization and focal adhesions, which are mainly regulated by Rho GTPases. Despite promising evidence, Rho GTPase inhibitors have not yet been successfully adopted for clinical use. The effects of terrein appear to be partly attributable to a decrease in the activity of Rho and Rac GTPases in these breast cancer cells. This indicates the potential of terrein as a therapeutic intervention as part of breast cancer therapy.

In addition to Rho GTPases, matrix metalloproteinases (MMPs) are also involved in migration, invasion, proliferation, and apoptosis. Six subclasses of MMPs including gelatinases, collagenases, stromelysins, matrilysins, membranetype MMPs and others are present in mammalian cells (41). Among these two gelatinases, MMP2 and MMP9, are often upregulated and strongly associated with breast cancer (42). Reduction of MMP2 and MMP9 levels was revealed to suppress growth and invasion of MCF-7 breast cancer cells (43-46). We determined that at a non-toxic $\operatorname{dose}(75 \mu \mathrm{M})$, terrein significantly reduced the number of invading cells in both cell lines, but to a lesser degree in MCF-7 cells. Downregulation of MMP-2 and MMP-9 transcription, as determined by real-time PCR, in both MDA-MB-231 and MCF-7 cells support our findings that terrein exerted an inhibitory effect on breast cancer cell invasion. Whether terrein directly contributes to transcriptional control of these genes is not clear and the precise mechanism will require further investigation. In vivo experiments on the activities of terrein would be more informative in terms of the effects on tumor growth and metastasis under physiological conditions and, therefore, need to be explored further. In addition to cell migration and invasion, animal experiments would also elucidate the effects of terrein on other important processes, including tumor growth, angiogenesis, and circulatory cancer cell survival.

Several links have been demonstrated between cell migration and invasion processes. Matsumoto et al in 2001 used Rho modulators to demonstrate that the Rho pathway was involved in MMP-2 activation. In addition, the regulation of Rho levels could modulate both cell motility and matrix degradation in osteosarcomas (47). Rac1 was also shown to mediate collagen-induced MMP-2 activation in fibrosarcoma cells (21). Consistent with these studies, SDF-1 $\alpha$ (or CXCL12), a chemokine known to stimulate cell adhesion and migration after binding to its G-protein-coupled receptor CXCR4, plays a key role in melanoma cell invasion $(48,49)$. The processes of migration and invasion have been demonstrated to involve stimulation of both Rho GTPases and MT1-MMP emphasizing their roles in cancer cells. Therefore, blocking the activity chain of these enzymes has the potential to inhibit cell invasiveness. The precise target of terrein was not identified in this study; however, one possibility is that terrein disrupts migration and invasion by interfering with chemokine receptor interaction.

In conclusion, this study is the first to demonstrate that terrein exhibits more than pro-apoptotic properties against cancer. The present study revealed that terrein inhibited the adhesion, migration, and invasion properties of breast cancer cells at non-toxic concentrations. The potential use of terrein in combination with other chemotherapeutic drugs to suppress both cancer growth and metastasis appears promising however it requires further investigation.

\section{Acknowledgements}

The present study was financially supported by the MED-RES-200 (Basic/Applied Research) fund from the Faculty of Medicine, Srinakharinwirot University (A.K.) and Mahidol University (M.P. and T.K.). F.L. was supported by a New Research Grant (A31/2556), Mahidol University, Thailand. We thank Rattanavinan Hanchaina and Kritsada Jaisamak for excellent technical assistance and Dr Sittirak Roitrakul for help in chemical analysis. We sincerely thank Dr Laran Jensen for critical reading of the manuscript.

\section{References}

1. Torre LA, Islami F, Siegel RL, Ward EM and Jemal A: Global Cancer in Women: Burden and Trends. Cancer Epidemiol Biomarkers Prev 26: 444-457, 2017.

2. Miller KD, Siegel RL, Lin CC, Mariotto AB, Kramer JL, Rowland JH, Stein KD, Alteri R and Jemal A: Cancer treatment and survivorship statistics, 2016. CA Cancer J Clin 66: 271-289, 2016.

3. Siegel RL, Miller KD and Jemal A: Cancer statistics, 2016. CA Cancer J Clin 66: 7-30, 2016.

4. Lee S, Kim WG, Kim E, Ryoo IJ, Lee HK, Kim JN, Jung SH and Yoo ID: Synthesis and melanin biosynthesis inhibitory activity of (+/-)-terrein produced by Penicillium sp. 20135. Bioorg Med Chem Lett 15: 471-473, 2005. 
5. Malmstrøm J, Christophersen C, Barrero AF, Oltra JE, Justicia J and Rosales A: Bioactive metabolites from a marine-derived strain of the fungus Emericella variecolor. J Nat Prod 65: 364-367, 2002

6. Phattanawasin P,Pojchanakom K, Sotanaphun U,Piyapolrungroj N and Zungsontiporn S: Weed growth inhibitors from Aspergillus fischeri TISTR 3272. Nat Prod Res 21: 1286-1291, 2007.

7. Kim D-S, Lee H-K, Park S-H, Lee S, Ryoo IJ, Kim WG, Yoo ID, Na JI, Kwon SB and Park KC: Terrein inhibits keratinocyte proliferation via ERK inactivation and G2/M cell cycle arrest. Exp Dermatol 17: 312-317, 2008.

8. Zhang F, Mijiti M, Ding W, Song J, Yin Y, Sun W and Li Z: (+)-Terrein inhibits human hepatoma Bel 7402 proliferation through cell cycle arrest. Oncol Rep 33: 1191-1200, 2015.

9. Chen YF, Wang SY, Shen H, Yao XF, Zhang FL and Lai D: The marine-derived fungal metabolite, terrein, inhibits cell proliferation and induces cell cycle arrest in human ovarian cancer cells. Int J Mol Med 34: 1591-1598, 2014.

10. Liao WY, Shen CN, Lin LH, Yang YL, Han HY, Chen JW, Kuo SC, Wu SH and Liaw CC: Asperjinone, a nor-neolignan, and terrein, a suppressor of ABCG2-expressing breast cancer cells, from thermophilic Aspergillus terreus. J Nat Prod 75: 630-635, 2012.

11. Porameesanaporn Y, Uthaisang-Tanechpongtamb W, Jarintanan F, Jongrungruangchok $\mathrm{S}$ and Thanomsub Wongsatayanon B: Terrein induces apoptosis in HeLa human cervical carcinoma cells through p53 and ERK regulation. Oncol Rep 29: 1600-1608, 2013

12. Shibata A, Ibaragi S, Mandai H, Tsumura T, Kishimoto K, Okui T, Hassan NM, Shimo T, Omori K, Hu GF, et al: Synthetic terrein inhibits progression of head and neck cancer by suppressing angiogenin production. Anticancer Res 36: 2161-2168, 2016.

13. Cairns RA, Khokha R and Hill RP: Molecular mechanisms of tumor invasion and metastasis: An integrated view. Curr Mol Med 3: 659-671, 2003.

14. Liotta LA and Stetler-Stevenson WG: Tumor invasion and metastasis: An imbalance of positive and negative regulation. Cancer Res 51 (Suppl 18): 5054s-5059s, 1991.

15. Sahai E and Marshall CJ: RHO-GTPases and cancer. Nat Rev Cancer 2: 133-142, 2002

16. Ridley AJ: Rho GTPases and actin dynamics in membrane protrusions and vesicle trafficking. Trends Cell Biol 16: 522-529, 2006.

17. Ridley AJ: Rho GTPase signalling in cell migration. Curr Opin Cell Biol 36: 103-112, 2015.

18. Ridley AJ: Rho family proteins: Coordinating cell responses. Trends Cell Biol 11: 471-477, 2001.

19. Vega FM and Ridley AJ: The RhoB small GTPase in physiology and disease. Small GTPases: Nov 22, 2016 (Epub ahead of print). doi: $10.1080 / 21541248.2016 .1253528$

20. Bravo-Cordero JJ, Moshfegh Y, Condeelis J and Hodgson L: Live cell imaging of RhoGTPase biosensors in tumor cells. Methods Mol Biol 1046: 359-370, 2013.

21. Zhuge $\mathrm{Y}$ and $\mathrm{Xu}$ J: Rac1 mediates type I collagen-dependent MMP-2 activation. Role in cell invasion across collagen barrier. J Biol Chem 276: 16248-16256, 2001.

22. Gebäck T, Schulz MM, Koumoutsakos P and Detmar M TScratch: A novel and simple software tool for automated analysis of monolayer wound healing assays. Biotechniques 46 : 265-274, 2009

23. Asano T, Tada M, Cheng S, Takemoto N, Kuramae T, Abe M, Takahashi O, Miyamoto M, Hamada J, Moriuchi T, et al: Prognostic values of matrix metalloproteinase family expression in human colorectal carcinoma. J Surg Res 146: 32-42, 2008.

24. Wanichwatanadecha P, Sirisrimangkorn S, Kaewprag J and Ponglikitmongkol M: Transactivation activity of human papillomavirus type $16 \mathrm{E} 6 * \mathrm{I}$ on aldo-keto reductase genes enhances chemoresistance in cervical cancer cells. J Gen Virol 93: 10811092,2012

25. Schmittgen TD and Livak KJ: Analyzing real-time PCR data by the comparative C(T) method. Nat Protoc 3: 1101-1108, 2008.

26. Koujan SE, Gargarib BP, Pirouzpanah S and Khalili M: Matrix metalloproteinases and breast cancer. Thrita 4: e21959, 2015.

27. Prudnikova TY, Rawat SJ and Chernoff J: Molecular pathways: Targeting the kinase effectors of RHO-family GTPases. Clin Cancer Res 21: 24-29, 2015.

28. Cherigo L, Lopez D and Martinez-Luis S: Marine natural products as breast cancer resistance protein inhibitors. Mar Drugs 13: 2010-2029, 2015.
29. Demasi M, Felicio A, Pacheco A, Leite H, Limaa C and Andrade L: Studies on terrein as a new class of proteasome inhibitors. J Braz Chem Soc 21: 299-305, 2010.

30. Adams $\mathbf{J}$ and Kauffman M: Development of the proteasome inhibitor Velcade (Bortezomib). Cancer Invest 22: 304-311, 2004

31. Mandai H, Omori K, Yamamoto D, Tsumura T, Murota K, Yamamoto S, Mitsudo K, Ibaragi S, Sasaki A, Maeda H, et al: Synthetic (+)-terrein suppresses interleukin-6/soluble interleukin-6 receptor induced-secretion of vascular endothelial growth factor in human gingival fibroblasts. Bioorg Med Chem 22: 5338-5344, 2014.

32. Lee YH, Lee SJ, Jung JE, Kim JS, Lee NH and Yi HK: Terrein reduces age-related inflammation induced by oxidative stress through Nrf2/ERK1/2/HO-1 signalling in aged HDF cells. Cell Biochem Funct 33: 479-486, 2015.

33. Cirit M, Grant KG and Haugh JM: Systemic perturbation of the ERK signaling pathway by the proteasome inhibitor, MG132. PLoS One 7: e50975, 2012 .

34. Vega FM and Ridley AJ: Rho GTPases in cancer cell biology. FEBS Lett 582: 2093-2101, 2008

35. Fritz G, Just I and Kaina B: Rho GTPases are over-expressed in human tumors. Int J Cancer 81: 682-687, 1999.

36. Chan AY, Coniglio SJ, Chuang YY, Michaelson D, Knaus UG, Philips MR and Symons M: Roles of the Rac1 and Rac3 GTPases in human tumor cell invasion. Oncogene 24: 7821-7829, 2005

37. Gadea G, Sanz-Moreno V, Self A, Godi A and Marshall CJ: DOCK10-mediated Cdc42 activation is necessary for amoeboid invasion of melanoma cells. Curr Biol 18: 1456-1465, 2008.

38. Nassar N, Cancelas J, Zheng J, Williams DA and Zheng Y: Structure-function based design of small molecule inhibitors targeting Rho family GTPases. Curr Top Med Chem 6: 1109-1116, 2006.

39. Akbar H, Cancelas J, Williams DA, Zheng J and Zheng Y: Rational design and applications of a Rac GTPase-specific small molecule inhibitor. Methods Enzymol 406: 554-565, 2006.

40. Montalvo-Ortiz BL, Castillo-Pichardo L, Hernández E, Humphries-Bickley T, De la Mota-Peynado A, Cubano LA, Vlaar CP and Dharmawardhane S: Characterization of EHop-016, novel small molecule inhibitor of Rac GTPase. J Biol Chem 287: 13228-13238, 2012.

41. Nagase H, Visse R and Murphy G: Structure and function of matrix metalloproteinases and TIMPs. Cardiovasc Res 69: 562-573, 2006.

42. Brown GT and Murray GI: Current mechanistic insights into the roles of matrix metalloproteinases in tumour invasion and metastasis. J Pathol 237: 273-281, 2015.

43. Mitropoulou TN, Tzanakakis GN, Kletsas D, Kalofonos HP and Karamanos NK: Letrozole as a potent inhibitor of cell proliferation and expression of metalloproteinases (MMP-2 and MMP-9) by human epithelial breast cancer cells. Int J Cancer 104: 155-160, 2003.

44. Farabegoli F, Govoni M, Spisni E and Papi A: EGFR inhibition by (-)-epigallocatechin-3-gallate and IIF treatments reduces breast cancer cell invasion. Biosci Rep 37: BSR20170168, 2017.

45. Lou C, Zhu Z, Zhao Y, Zhu R and Zhao H: Arctigenin, a lignan from Arctium lappa L., inhibits metastasis of human breast cancer cells through the downregulation of MMP-2/-9 and heparanase in MDA-MB-231 cells. Oncol Rep 37: 179-184, 2017.

46. Bakar F, Kilic-Kurt Z, Caglayan MG and Olgen S: The effects of 1,3,5-trisubstituted indole derivatives on cell growth, apoptosis and MMP-2/9 mRNA expression of MCF-7 human breast cancer cells. Anticancer Agents Med Chem 17: 762-767, 2017.

47. Matsumoto Y, Tanaka K, Harimaya K, Nakatani F, Matsuda S and Iwamoto Y: Small GTP-binding protein, Rho, both increased and decreased cellular motility, activation of matrix metalloproteinase 2 and invasion of human osteosarcoma cells. Jpn J Cancer Res 92: 429-438, 2001.

48. Aiuti A, Webb IJ, Bleul C, Springer T and Gutierrez-Ramos JC The chemokine SDF-1 is a chemoattractant for human CD34+ hematopoietic progenitor cells and provides a new mechanism to explain the mobilization of $\mathrm{CD} 34^{+}$progenitors to peripheral blood. J Exp Med 185: 111-120, 1997.

49. Bartolomé RA, Molina-Ortiz I, Samaniego R, Sánchez-Mateos P, Bustelo XR and Teixidó J: Activation of Vav/Rho GTPase signaling by CXCL12 controls membrane-type matrix metalloproteinase-dependent melanoma cell invasion. Cancer Res 66: 248-258, 2006 